\title{
Membrane Cholesterol Is Crucial for Clostridium difficile Surface Layer Protein Binding and Triggering Inflammasome Activation
}

\begin{abstract}
Yu Chen ${ }^{1 \dagger}$, Kai Huang ${ }^{2 \dagger}$, Liang-Kuei Chen ${ }^{2,3}$, Hui-Yu Wu ${ }^{1}$, Chih-Yu Hsu ${ }^{2}$, Yau-Sheng Tsai ${ }^{4}$, Wen-Chien $\mathrm{Ko}^{5}$ and Pei-Jane Tsai ${ }^{2,3,6 *}$

${ }^{1}$ Department of Laboratory Medicine, Mackay Memorial Hospital, New Taipei, Taiwan, ${ }^{2}$ Department of Medical Laboratory Science and Biotechnology, National Cheng Kung University, Tainan, Taiwan, ${ }^{3}$ Department of Pathology, National Cheng Kung University Hospital, Tainan, Taiwan, ${ }^{4}$ Institute of Clinical Medicine, National Cheng Kung University, Tainan, Taiwan, ${ }^{5}$ Department of Internal Medicine, National Cheng Kung University Hospital, Tainan, Taiwan, ${ }^{6}$ Center of Infectious Disease and Signaling Research, National Cheng Kung University, Tainan, Taiwan
\end{abstract}

OPEN ACCESS

Edited by:

Chih-Ho Lai,

Chang Gung University, Taiwan

Reviewed by:

Cheng-Hsun Chiu,

Chang Gung Children's

Hospital, Taiwan

Chih-Feng Kuo,

I-Shou University, Taiwan

${ }^{*}$ Correspondence:

Pei-Jane Tsai

peijtsai@mail.ncku.edu.tw

${ }^{\dagger}$ These authors have contributed equally to this work

Specialty section:

This article was submitted to

Microbial Immunology,

a section of the journal

Frontiers in Immunology

Received: 30 April 2020

Accepted: 23 June 2020

Published: 31 July 2020

Citation:

Chen Y, Huang $K$, Chen L-K, Wu H-Y,

Hsu C-Y, Tsai Y-S, Ko W-C and

Tsai P-J (2020) Membrane Cholesterol

Is Crucial for Clostridium difficile

Surface Layer Protein Binding and

Triggering Inflammasome Activation.

Front. Immunol. 11:1675

doi: 10.3389/fimmu.2020.01675
Clostridium difficile, an obligate anaerobic gram-positive bacillus, generates spores and is commonly found colonizing the human gut. Patients with $C$. difficile infection (CDI) often exhibit clinical manifestations of pseudomembranous colitis or antibiotic-associated diarrhea. Surface layer proteins (SLPS) are the most abundant proteins in the C. difficile cell wall, suggesting that they might involve in immune recognition. Our previous results demonstrated that $C$. difficile triggers inflammasome activation. Here, we found SLPS as well as $C$. difficile induced inflammasome activation, and in a dose-dependent manner. In addition, the cholesterol-rich microdomains on the cell membrane (also referred to as lipid rafts) are thought to be crucial for bacterial adhesion and signal transduction. We demonstrated that lipid rafts participated in C. difficile SLPS binding to the cell membrane. Fluorescence microscopy showed that membrane cholesterol depletion by methyl- $\beta$-cyclodextrin (M $\beta C D$ ) reduced the association of SLPs with the cell surface. The coalescence of SLPS in the cholesterol-rich microdomains was confirmed in C. difficile-infected cells. Furthermore, the inflammasome activations induced by SLPS or $C$. difficile were abrogated by $M \beta C D$. Our results demonstrate that SLPs recruit the lipid rafts, which may be a key step for C. difficile colonization and inducing inflammasome activation.

Keywords: Clostridium difficile, membrane cholesterol, lipid rafts, surface layer proteins, inflammasome activation

\section{INTRODUCTION}

C. difficile, an anaerobic gram-positive spore-forming bacillus, is known as one of the most important nosocomial pathogens, and usually causes health care facility-associated infections (1). C. difficile is mainly transmitted through the oral-fecal route by spores that are dormant cells, which are highly resistant to the gastric acidic environment (2). Most importantly, C. difficile infection (CDI) in the colon is often life-threatening, particularly in the immunocompromised elderly and in patients who have intestinal dysbiosis following antimicrobial drug exposure (3). Moreover, 
manipulation of toxin secretion and bacterial architecture are crucial for $C$. difficile to colonize the colon, which subsequently induces host inflammation and pathogenesis (4).

Virulent strains of $C$. difficile possess three toxins: toxin A $(\operatorname{Tcd} \mathrm{A})$, toxin B $(\mathrm{TcdB})$, and a binary toxin (C. difficile transferase, CDT), which have been shown to cause bacteriainduced pathogenesis (5). In addition to toxin production, $C$. difficile is found to have surface layers (S-layers) that completely coat the entire vegetative cells and play important roles in bacterial adhesion to enteric cells (6). C. difficile S-layers contain two S-layer proteins (SLPs): a conserved high molecular weight (HMW, 42-48 kDa) SLP and a highly variable low molecular weight (LMW, 32-38 kDa) SLP. Both these SLPs are derived from the post-translational cleavage of surface layer protein A (SlpA), which is encoded by a single gene $\operatorname{slp} A(7)$.

The host innate immune system is the first line of defense against microbial infection and is activated by the engagement of pattern-recognition receptors (PRRs) that are responsible for recognizing specific components expressed by the microbes (8). Previous studies suggested that inflammasome activation is involved in $C$. difficile pathogenesis through several different mechanisms. $\mathrm{Ng}$ et al. (9) were the first researchers to demonstrate that inflammasome activation is involved in $C$. difficile infection. Our recent study also demonstrated that the caspase-1-dependent inflammasome plays an important role regulating host defense during $C$. difficile infection (10). Although the molecular mechanism of the $C$. difficile toxininduction is well-understood, the interactions of this pathogen, either directly or indirectly, with the host innate and adaptive immune system are poorly understood.

Lipid rafts are cholesterol-rich microdomains localized in the cell membrane (11). Several pathogens, including their virulence factors, exploit lipid rafts for entering host cells (12-15). It has been shown that CDT-induced microtubule-based membrane protrusions depend on lipid rafts in enteric cells $(16,17)$. Moreover, membrane cholesterol is crucial for the delivery of C. difficile toxins, TcdA and TcdB, into host cells (18). However, whether SLPs interact with lipid rafts remains to be illustrated. In this study, we explored the involvement of SLPs in triggering inflammasome activation and the association of SLPs with the cell membrane in a cholesterol-dependent manner. We further investigated whether lipid rafts are involved in C. difficile induced inflammasome activation.

\section{MATERIALS AND METHODS \\ Cell Culture}

CHO-K1 cells (Chinese hamster ovary cells; ATCC CCL-61) were cultured in F12 medium (Gibco, Grand Island, NY, USA) supplemented with 10\% FBS (Biological Industries, Cromwell, CT, USA). The cells were incubated at $37^{\circ} \mathrm{C}$ in a humid atmosphere containing 5\% $\mathrm{CO}_{2}$. THP-1 cells (Human acute monocytic leukemia cells) was obtained from Bioresource Collection and Research Center (BCRC), Hsinchu, Taiwan. THP1 cells were cultured in LPS-free RPMI1640 medium (Gibco) supplemented with 10\% FBS (Biological Industries). THP-1 cells were differentiated with $100 \mathrm{nM}$ phorbol 12-myristate 13 acetate (PMA) treatment for $24 \mathrm{~h}$ prior to $C$. difficile infection or SLPs exposure.

\section{Bacterial Culture}

C. difficile CCUG $37780\left(t c d A^{-}, t c d B^{-}\right)$, a non-toxigenic strain, was cultured on CDC anaerobe 5\% sheep blood agar (Becton Dickinson, Cockeysville, MD, USA) in a $37^{\circ} \mathrm{C}$ incubator for 2 days under the condition anaerobic gas generator (Mitsubishi ${ }^{\mathrm{TM}}$ AnaeroPack-Anaero, Japan) as described previously (19). The bacterial colonies were grown in Brain-Heart Infusion (BHI) broth (Becton Dickinson) supplemented with $5 \mathrm{mg} / \mathrm{ml}$ yeast extract and $0.1 \% \mathrm{~L}$-cysteine (Amresco, Solon, $\mathrm{OH}, \mathrm{USA}$ ) at $37^{\circ} \mathrm{C}$ for 2 days. The bacteria were washed with $1 \times$ PBS prior to macrophage infection.

\section{Preparation of Surface Layer Proteins (SLPs)}

The extraction method was modified from a previous study (20). Briefly, overnight culture of $C$. difficile was collected, and the SLPs was extracted by $0.2 \mathrm{M}$ glycine, $\mathrm{pH}$ 2.2. After removing the bacterial components, the supernatant was neutralized with $2 \mathrm{M}$ Tris-HCI. To increase the purity of SLPs, the neutralized supernatant was filtered by $50 \mathrm{kDa}$ molecular weight-cutoff centrifugation-based filters (Millipore). Then the filtrate was concentrated by $30 \mathrm{kDa}$ centrifugation-based filters (Millipore).

\section{SDS-PAGE and Western Blot Assays}

Purified SLPs were boiled in SDS-PAGE sample buffer for $10 \mathrm{~min}$ and subjected to $10 \%$ SDS-PAGE. The gel was stained with Coomassie Brilliant Blue R-250 (Amresco) for visualization of SLPs. In addition, the gel was transferred onto polyvinylidene difluoride membranes (PVDF, Millipore, Billerica, MA, USA). The membranes were blocked with TBST containing 5\% skim milk for $1 \mathrm{~h}$ and then incubated with anti-SLPs antibody followed by incubation with HRP-conjugated secondary antibodies (Millipore) for $1 \mathrm{~h}$. The proteins of interest were detected using ECL western blotting detection reagents (GE Healthcare, Chicago, IL, USA), and were visualized using Azure c400 system and AzureSpot Analysis Software (Azure Biosystems; Dublin, CA, USA) according to the manufacturer's instructions.

For monitoring caspase- 1 and IL- $1 \beta$ maturation, total proteins were separated by SDS-PAGE, transferred to PVDF membranes, and probed with antibodies against IL-1 $\beta$ (R\&D system, Minneapolis, MN, USA), precursor and p10 subunit of caspase1 (Abcam, Cambridge, United Kingdom) and $\beta$-actin (SigmaAldrich, St. Louis, Missouri, USA). The expression of lowmolecular-weight (LMW) surface layer proteins in the cell culture supernatant was also detected using rabbit anti-LMW SLP BAA 1805 serum (customized by Abnova, Taipei, Taiwan).

\section{Flow Cytometric Analysis}

To analyze the binding of SLPs to lipid rafts, CHO-K1 cells treated with $C$. difficile SLPs were analyzed by flow cytometry. CHO-K1 cells $\left(7 \times 10^{5}\right)$ were pretreated with $10 \mathrm{mM}$ methyl- $\beta$ cyclodextrin (M $\beta C D$, Sigma-Aldrich Saint Louis, MO, USA), a cholesterol depletion agent commonly used to extract cholesterol 


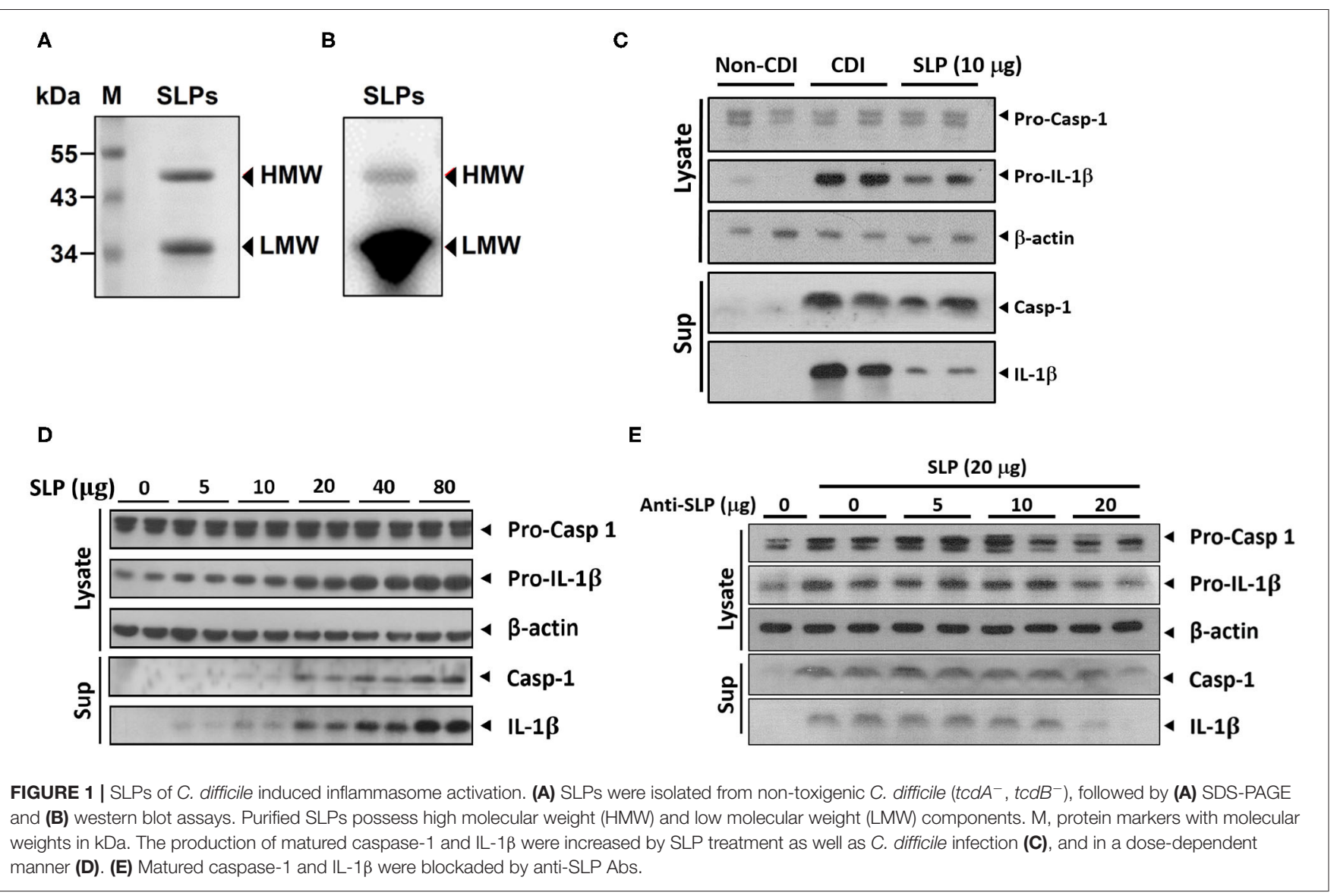

from lipid rafts, for $1 \mathrm{~h}$, and then treated with SLPs $(20 \mu \mathrm{g} / \mathrm{ml})$ at $4^{\circ} \mathrm{C}$ for an additional $2 \mathrm{~h}$. The green fluorescent intensity of SLPs probed with fluorescein isothiocyanate (FITC)-conjugated goat anti-rabbit IgG was analyzed by flow cytometry (FACSCalibur Cell Analyzer, Becton Dickinson).

\section{Immunofluorescence Microscopy}

To visualize the localization of SLPs on cell membrane, CHO$\mathrm{K} 1$ cells $\left(1 \times 10^{6}\right)$ were seeded on coverslips in a $6-\mathrm{cm}$ dish and incubated for $10 \mathrm{~h}$. Cells were pretreated with $10 \mathrm{mM} \mathrm{M \beta CD}$ and then exposed to SLPs $(20 \mu \mathrm{g} / \mathrm{ml})$ at $11^{\circ} \mathrm{C}$ for $1 \mathrm{~h}$ to maintain the fluidity of the cell membrane and to prevent the internalization of cells. Cells were infected with $C$. difficile at a MOI of 20 and incubated at $37^{\circ} \mathrm{C}$ for $6 \mathrm{~h}$. The treated cells were then washed with $1 \times \mathrm{PBS}$ and fixed with $4 \%$ paraformaldehyde (Sigma-Aldrich). The cells were probed with anti-caveolin-1conjugated FITC antibody (Santa Cruz Biotechnology, Santa Cruz, CA), which is a marker for staining membrane rafts. The cells were then incubated with anti-SLP antibody, followed by Alexa Fluor red 555-conjugated goat anti-rabbit IgG (Invitrogen, Carlsbad, CA). Nuclei were counterstained with Hoechst 33,342. The samples were observed under a confocal laser-scanning microscope (LSM780, ZEISS, Germany). The quantification of fluorescence intensity for SLPs and caveolin-1 was analyzed using ZEN software (Carl Zeiss, Göttingen, Germany).

\section{Statistical Analysis}

Experimental results are expressed as mean \pm SEM. Student's $t$-test was used to determine the statistical significance of the differences between two groups. Differences were considered significant when $P<0.05$. Statistical analysis was performed using Prism6 (GraphPad Software, La Jolla, CA, USA).

\section{RESULTS}

\section{C. difficile SLPs Induce Inflammasome Activation}

Previous studies suggested that SLPs of C. difficile could induce production of proinflammatory cytokines including IL$1 \beta$ (21). Therefore, we tried to examine whether SLPs induce inflammasome activation. We purified SLPs, including low and high molecular weight SLPs from the non-toxigenic $C$. difficile strain CCUG 37780. The purified SLPs were analyzed using 10\% SDS-PAGE and western blot assays. As shown in Figures 1A,B, C. difficile SLPs contained two components: HMW and LMW with molecular weights of 45 and $34 \mathrm{kDa}$, respectively. After treating THP-1 cells with purified SLPs or C. difficile infection (CDI), the production of matured caspase1 and IL-1 $\beta$ were increased when compared to non-CDI control group (Figure 1C). Noticeably, SLPs-induced caspase1 and IL-1 $\beta$ production were in dose-dependent manners 


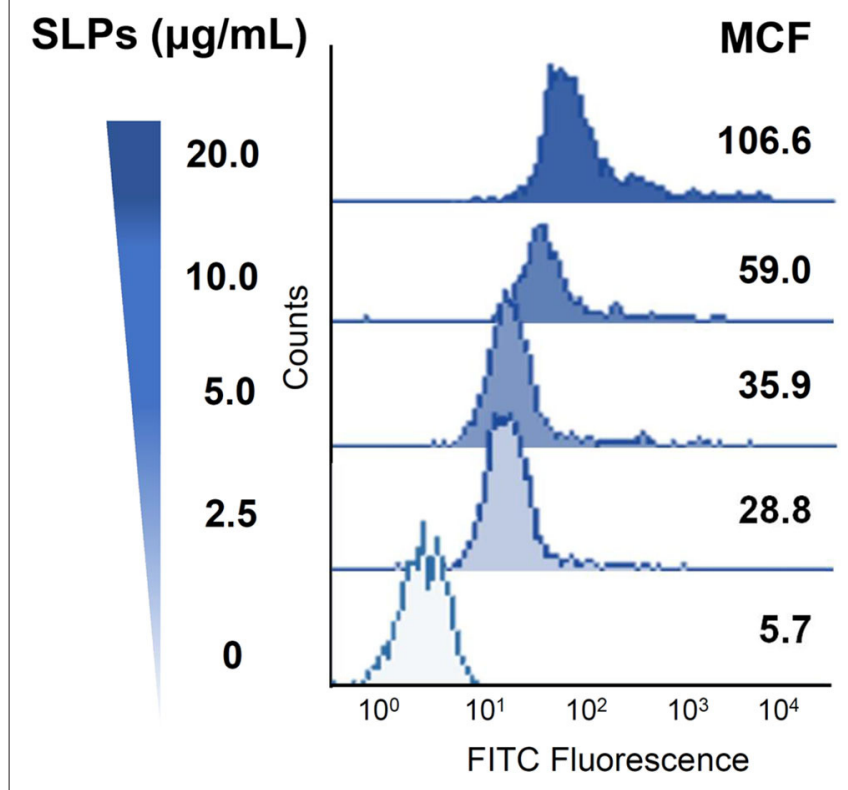

FIGURE 2 | Binding of C. difficile SLPs to cells. CHO-K1 cells were exposed to various concentrations of SLPs $(0-20 \mu \mathrm{g} / \mathrm{ml})$ and incubated at $4^{\circ} \mathrm{C}$ for $2 \mathrm{~h}$. The cells were probed with the anti-SLP antibody at $4^{\circ} \mathrm{C}$ for $2 \mathrm{~h}$, followed by incubation with FITC-conjugated goat anti-rabbit IgG. The binding activity of SLPS was assessed using flow cytometry to detect FITC fluorescence intensity. MCF, mean channel fluorescence.
(Figure 1D). Moreover, blockage of SLPs with SLP antibody dose-dependently decreased the production of caspase- 1 and IL-1 $\beta$ (Figure 1E). These results showed that SLPs can induce inflammasome activation.

\section{C. difficile SLPs Bind to the Cell Membrane}

We then investigated whether $C$. difficile SLPs interact with the cell membrane; $\mathrm{CHO}-\mathrm{K} 1$ cells were used as assay platforms. Cells were treated with various concentrations of SLPs at $4^{\circ} \mathrm{C}$ for $2 \mathrm{~h}$. The treated cells were then analyzed using flow cytometry. Figure 2 showed that with the elevation of SLP concentrations $(0-20 \mu \mathrm{g} / \mathrm{ml})$, the binding of SLPs on the cell membrane gradually increased.

We next explored whether cholesterol depletion affects the binding of SLPs to cells. CHO-K1 cells were pretreated with $\mathrm{M} \beta \mathrm{CD}$ at $37^{\circ} \mathrm{C}$ for $1 \mathrm{~h}$ to deplete cholesterol from cells. As shown in Figure 3, the mean channel fluorescence (MCF) for SLP binding to cells was reduced in cells pretreated with $\mathrm{M} \beta C D$ as compared to that in the untreated control cells. These results indicate that SLPs bind to the membrane where the lipid rafts are localized.

\section{Depletion of Cellular Cholesterol Reduces SLP Binding to the Cell Membrane}

We used confocal microscopy to visualize whether SLP binding to cells is dependent on the lipid rafts. CHO-K1 cells were either untreated or pretreated with $10 \mathrm{mM} \mathrm{M \beta CD}$ for $1 \mathrm{~h}$ at $37^{\circ} \mathrm{C}$, prior to exposure to $20 \mu \mathrm{g} / \mathrm{ml}$ SLPs at $11^{\circ} \mathrm{C}$ for $1 \mathrm{~h}$.

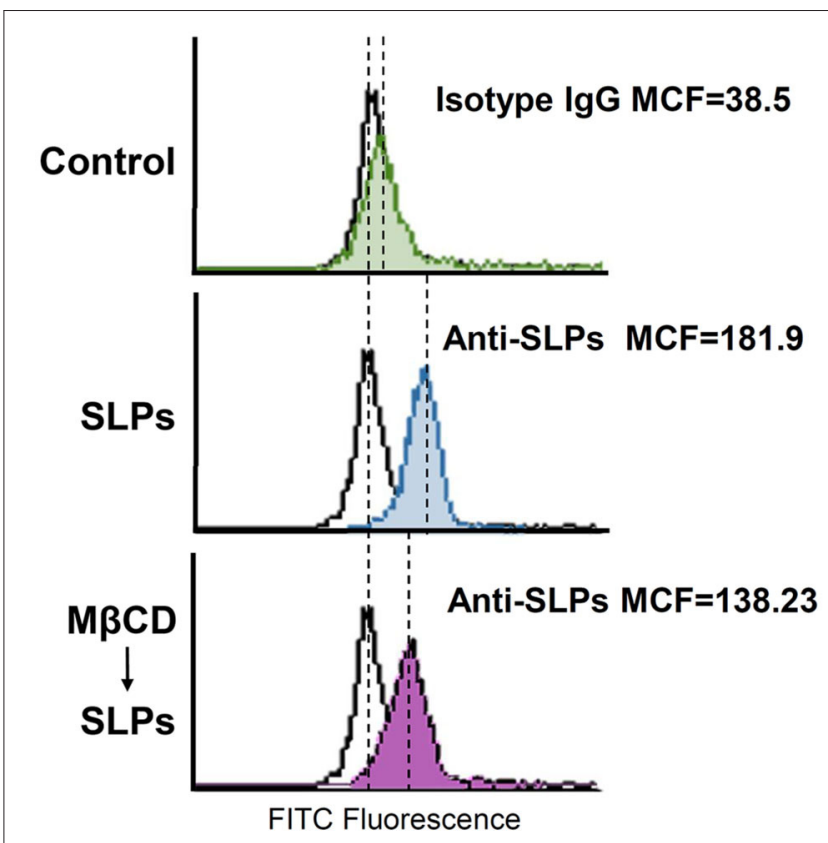

FIGURE 3 | Sufficient cholesterol is essential for SLP binding to cells. CHO-K1 cells were untreated or pretreated with $10 \mathrm{mM} \mathrm{M \beta CD}$ at $37^{\circ} \mathrm{C}$ for $1 \mathrm{~h}$, followed by exposure to SLPs $(20 \mu \mathrm{g} / \mathrm{ml})$. After treatment with the anti-SLP antibody at $4^{\circ} \mathrm{C}$ for $2 \mathrm{~h}$, the cells were stained with FITC-conjugated goat anti-rabbit IgG. The binding activity of SLPs was assessed using flow cytometry to detect FITC fluorescence intensity. MCF, mean channel fluorescence.

Cells were probed with the anti-caveolin-1 antibody to identify the membrane raft microdomains. As shown in Figure 4, the control cells untreated with SLPs did not show red fluorescence signal; however, caveolin-1 (green) was observed around the membrane (first row). When cells were pretreated with $10 \mathrm{mM}$ $\mathrm{M} \beta \mathrm{CD}$, cell membrane caveolin-1 was reduced (second row). Cells incubated with SLPs showed considerable colocalization with the membrane raft marker caveolin-1 (third row, merged in yellow). After pretreating cells with $\mathrm{M} \beta \mathrm{CD}$ to deplete cholesterol, followed by incubation with SLPs, the overlay of the yellow fluorescent signal was weaker (fourth row) than that in cells untreated with $\mathrm{M} \beta \mathrm{CD}$. These results indicate that SLPs isolated from $C$. difficile possess binding activity to lipid rafts on the cell surface.

\section{Interaction of Clostridium difficile SLPs With Membrane Rafts}

We then used cells infected with $C$. difficile to verify the interactions between bacterial SLPs and lipid rafts. In the absence of C. difficile infection, there was no SLP signal (Figure 5). C. difficile infected cells showed that SLPs were abundantly distributed around the cytoplasm as well as the membrane, as indicated by the colocalized caveolin-1. In contrast, pretreatment of cells with $10 \mathrm{mM} \mathrm{M} \beta \mathrm{CD}$ reduced the colocalization signals of SLPs and caveolin-1. These results demonstrate that upon infection by $C$. difficile, SLPs bind to the membrane that has cholesterol-rich microdomains. 


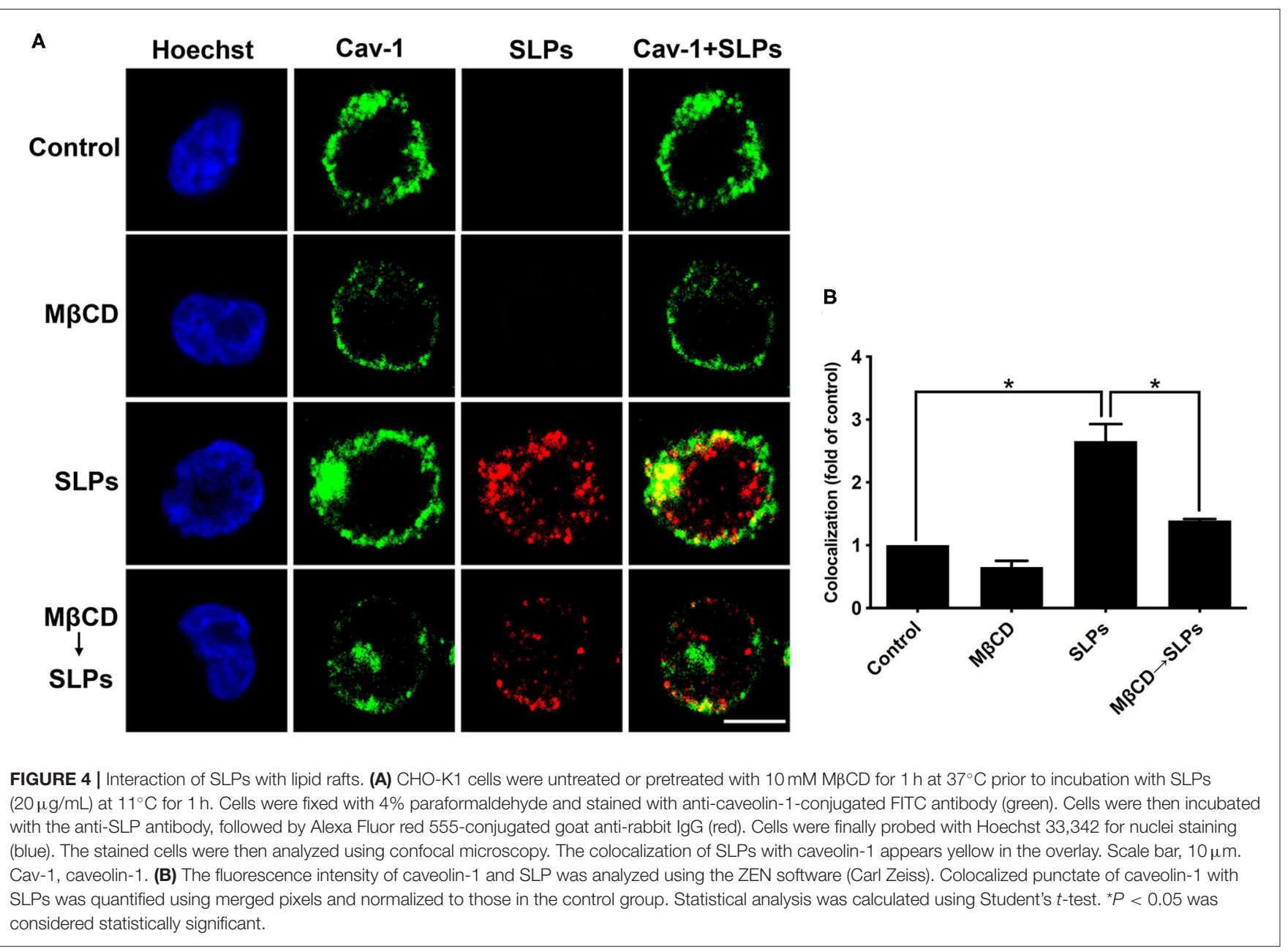

\section{Depletion of Cellular Cholesterol Diminishes the Inflammasome Activation Induced by SLPs and C. difficile}

To connect the relationship between inflammasome activation induced by SLPs or $C$. difficile with lipid rafts, M $B C D$ pretreated cells were examined for the inflammasome activation. In the SLPs treated cells showed the abundant proinflammatory cytokine IL- $1 \beta$ upon compared to the negative control (NC), and the activation of the inflammasome was reduced while the cells were depleted cholesterol by M $\beta C D$ (Figure 6A). In addition, we further investigated the inflammasome activation triggered by $C$. difficile infection. The results showed that the $C$. difficile infection can trigger IL- $1 \beta$ maturation and this activation was reduced by the pretreatment with $\mathrm{M} \beta \mathrm{CD}$ (Figure 6B). Both results demonstrate that the SLPs as well as $C$. difficile induced the inflammasome activation mediated through the lipid rafts.

\section{DISCUSSION}

SLPs provide structural integrity to the bacterial cells and participate in the adhesion to host cells (22-24). Although SLPs have been recognized as virulence factors for bacteria-induced pathogenesis, the receptors for SLP binding to cells need to be explored. In this study, we found that cellular cholesterol plays a pivotal role in $C$. difficile SLP binding and triggering inflammasome activation. Investigating the interactions between bacterial virulence factors and cell receptors is particularly crucial because these key molecules have been proposed as possible targets for treating bacterial infectious diseases.

Purified SLPs from $C$. difficile can be recognized by Tolllike receptor 4 (TLR4), which activates inflammatory responses and contributes to CDI pathogenesis (25). Moreover, SLPs of C. difficile are capable of inducing proinflammatory cytokines, including IL-1 $\beta$, IL-12, IL-23, and TNF- $\alpha(21,26)$. Our recent study further demonstrated that SLPs were released from damaged cells via caspase-1-mediated regulation (10). These findings indicate that SLPs possess the ability to orchestrate the immune response during CDI pathogenesis. Furthermore, we also discovered that inflammasome activation was induced by SLPs during $C$. difficile infection, suggesting that the SLPs play an important role in regulating host defense against $C$. difficile infection.

Lipid rafts on the cell membrane are enriched in cholesterol and sphingolipids, and play crucial roles in various cellular processes, including membrane trafficking, signal transduction, 


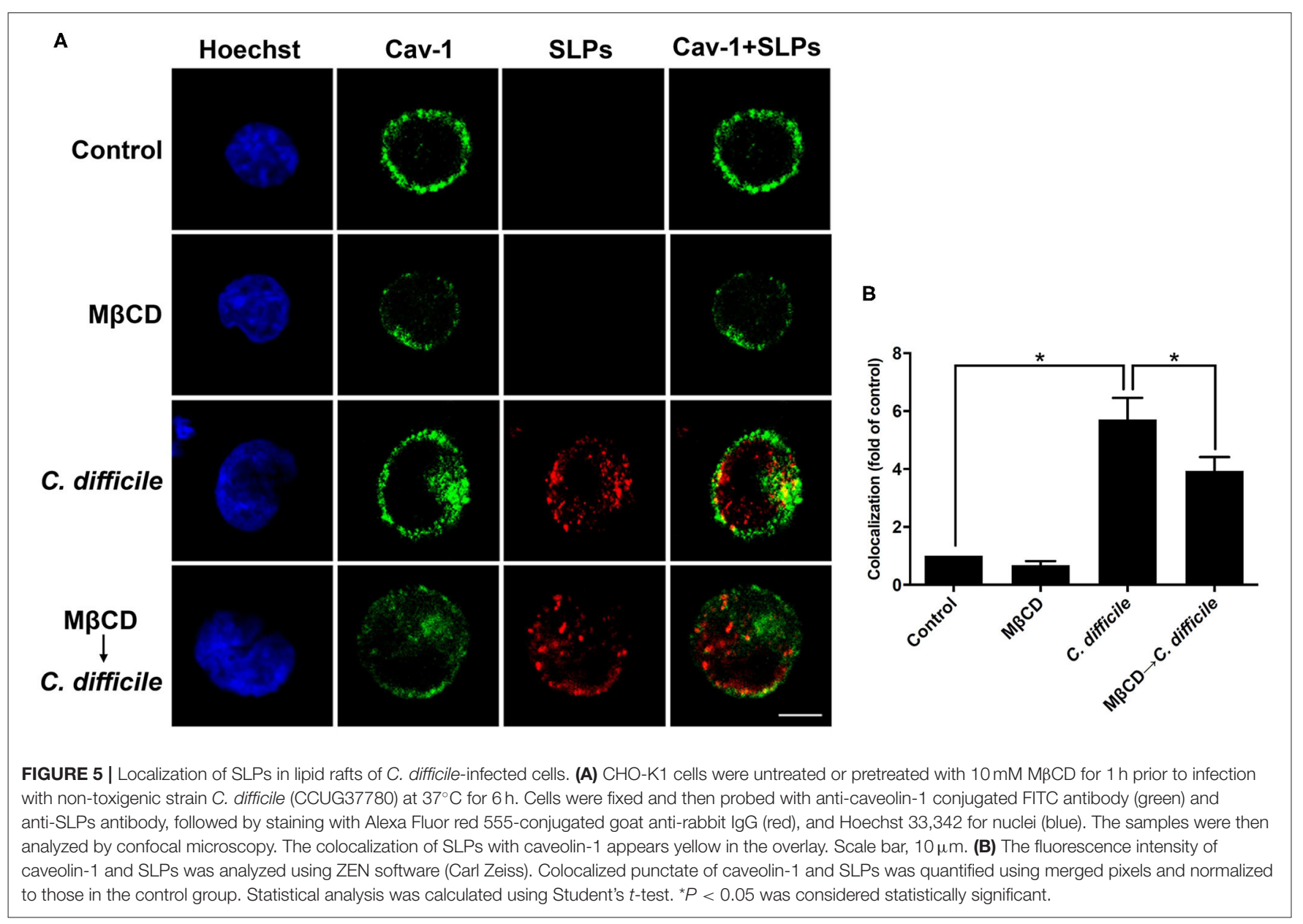

cytoskeletal rearrangement, and pathogen entry (27-29). Most importantly, lipid rafts also function as internalized portals for the entry of bacterial toxins, which contribute to severe infectious diseases including shigellosis and anthrax $(12,30)$. The study on $C$. difficile toxin has demonstrated that CDT-induced microtubule-based membrane protrusions were dependent on cholesterol-rich microdomains present in the human colon cells (16). Moreover, the active subunit of CDT, called CDTb, that binds to the lipolysis-stimulated lipoprotein receptor (LSR) was found to coalesce into lipid rafts (17). In this study, we further demonstrated that $C$. difficile SLPs interact with the cell membrane rich in lipid rafts. Together, these findings indicate that both CDT and SLPs interact with raft-microdomains, subsequently inducing the $C$. difficile infection process and pathogenic response in the intestinal epithelial cells.

Colonization is an essential process that interferes with the gut microbiota in C. difficile-induced pathogenesis (31). Many bacterial surface proteins contribute to the colonization of the host intestinal epithelium and subsequent multiplication in the gut surface and lumen (32). This study employed Chinese hamster ovary-K1 (CHO-K1) cells to investigate the association of $C$. difficile SLPs with the cell membrane. Our results showed that SLPs are capable of binding to the cell surface, in which activity was decreased when cellular cholesterol was depleted using M $\beta C D$. Many studies have used CHO-K1 cells as an assay model to analyze membrane-raft functions (33-35). Therefore, it appears that $\mathrm{CHO}-\mathrm{K} 1$ is a suitable model for exploring the relationship between $C$. difficile SLPs and lipid rafts. Interestingly, it has been reported that $\mathrm{CHO}-\mathrm{K} 1$ cells lack surface Toll-like receptors $(36,37)$. We speculate that in addition to TLR4, other molecules are involved in the mechanism of C. difficile SLP attachment to host cells.

Although $C$. difficile toxins are considered crucial for disease development, previous studies have reported that nontoxigenic $C$. difficile is also present in the stool samples of hospitalized patients with persistent diarrhea (38). Our results indicate that regardless of purified SLPs or direct infection of C. difficile to cells, similar trends were observed, which demonstrated that SLPs and lipid rafts are important for the C. difficile-induced inflammasome activation. This evidence further indicates that besides toxins, SLPs are also involved in C. difficile-associated diseases. However, the in-depth study of how $C$. difficile SLPs interact with lipid rafts has been hampered by the inability to establish a $\operatorname{sl} p A$-deficient mutant strain, which is the limitation of this study as well. Therefore, to overcome this limitation, a stable C. difficile SLP-knockout 
A

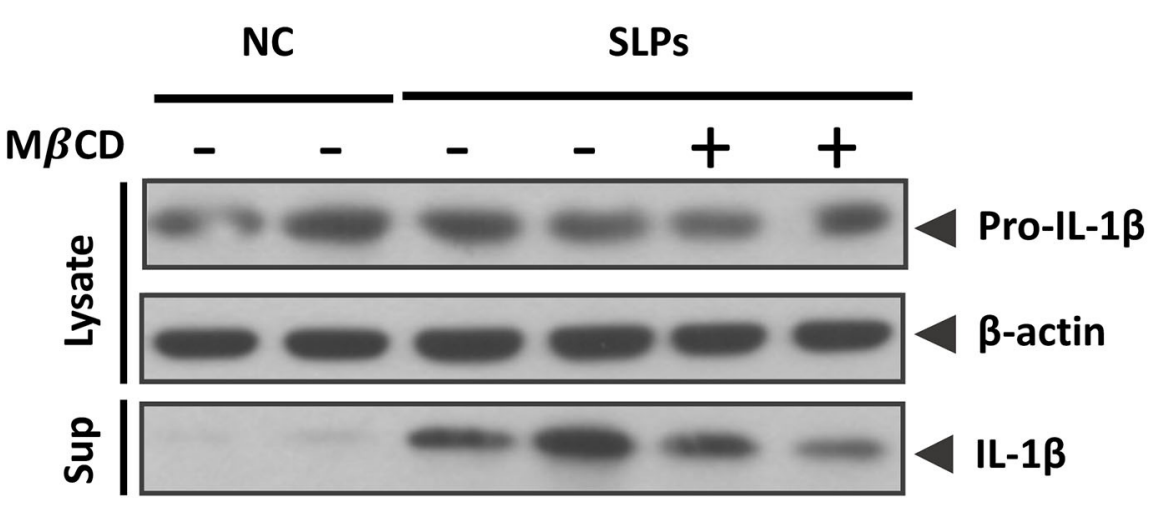

B

NC C. difficile

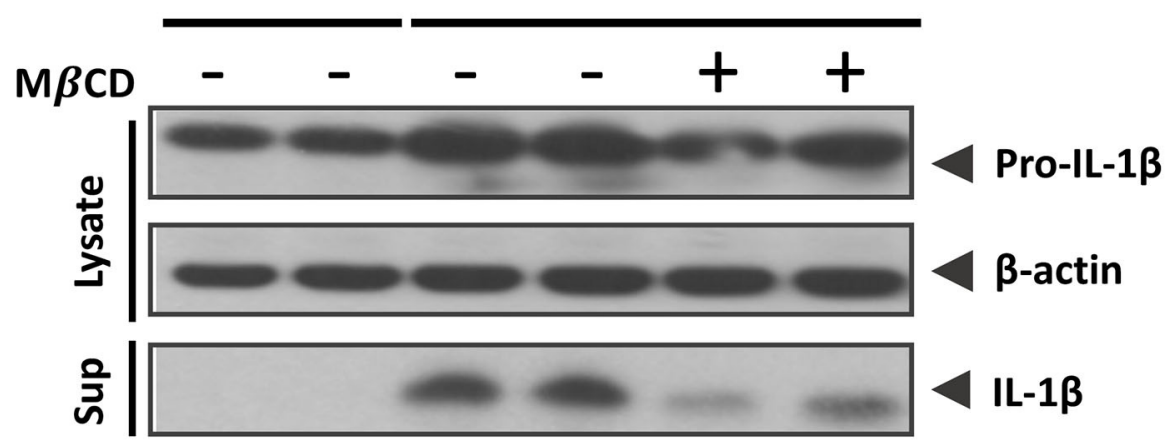

FIGURE 6 | Sufficient cholesterol is essential for C. difficile and SLPs-induced inflammasome activation. Western blot analysis of (A) IL-1 3 maturation either in cell lysate or supernatant after SLPs treatment, and (B) C. difficile infection.

strain is needed for further study. On the other hand, statins, a class of lipid-lowering medications, have pleiotropic effects beyond cholesterol lowering by immune modulation (39). The association of statins with CDI is unclear as clinical studies have reported conflicting findings $(40,41)$. Modifying the lipid rafts during CDI may provide potentially important novel alternative therapeutic targets to treat and prevent C. difficile infection.

\section{CONCLUSION}

This study demonstrates that membrane cholesterol plays important roles in C. difficile SLPs binding and triggering inflammasome activation. Disruption of lipid rafts reduces SLPs binding to cells and mitigates $C$. difficile-induced inflammasome activation. The membrane receptors that contribute to SLPs interaction with cholesterol-rich microdomains will be the subject of research in further studies. This novel discovery contributes to understanding the essential factors for $C$. difficile infection and enable the development of novel therapeutic strategies to prevent CDI.

\section{DATA AVAILABILITY STATEMENT}

All datasets presented in this study are included in the article.

\section{AUTHOR CONTRIBUTIONS}

$\mathrm{YC}, \mathrm{KH}, \mathrm{L}-\mathrm{KC}$, and $\mathrm{H}-\mathrm{YW}$ researched data, contributed to the discussion, and wrote the manuscript. Y-ST, C-YH, and W$\mathrm{CK}$ contributed to the discussion, and reviewed and edited the manuscript. P-JT contributed to the original concept and discussion, and wrote, reviewed, and edited the manuscript. All authors contributed to the article and approved the submitted version.

\section{FUNDING}

This work was supported by grants from the Ministry of Science and Technology (MOST 108-2321-B-006-004 and MOST 108-2320-B-006-043-MY3). This research was, in part, supported by the Ministry of Education, Taiwan, R.O.C. Headquarters of University Advancement to the National Cheng Kung University (NCKU). 


\section{REFERENCES}

1. Hung YP, Lee JC, Tsai BY, Wu JL, Liu HC, Liu HC, et al. Risk factors of Clostridium difficile-associated diarrhea in hospitalized adults: vary by hospitalized duration. J Microbiol Immunol Infect. (2019) S16841182(19)30088-X. doi: 10.1016/j.jmii.2019.07.004. [Epub ahead of print].

2. Awad MM, Johanesen PA, Carter GP, Rose E, Lyras D. Clostridium difficile virulence factors: insights into an anaerobic spore-forming pathogen. Gut Microbes. (2014) 5:579-93. doi: 10.4161/19490976.2014. 969632

3. Ghose C. Clostridium difficile infection in the twenty-first century. Emerg Microbes Infect. (2013) 2:e62. doi: 10.1038/emi.2013.62

4. Paredes-Sabja D, Shen A, Sorg JA. Clostridium difficile spore biology: sporulation, germination, and spore structural proteins. Trends Microbiol. (2014) 22:406-16. doi: 10.1016/j.tim.2014.04.003

5. Aktories K, Schwan C, Jank T. Clostridium difficile toxin biology. Annu Rev Microbiol. (2017) 71:281-307. doi: 10.1146/annurev-micro-090816093458

6. Fagan RP, Fairweather NF. Biogenesis and functions of bacterial S-layers. Nat Rev Microbiol. (2014) 12:211-22. doi: 10.1038/nrmicro3213

7. Kirk JA, Banerji O, Fagan RP. Characteristics of the Clostridium difficile cell envelope and its importance in therapeutics. Microb Biotechnol. (2017) 10:76-90. doi: 10.1111/1751-7915.12372

8. Monie TP, Bryant CE, Gay NJ. Activating immunity: lessons from the TLRs and NLRs. Trends Biochem Sci. (2009) 34:55361. doi: 10.1016/j.tibs.2009.06.011

9. Ng J, Hirota SA, Gross O, Li Y, Ulke-Lemee A, Potentier MS, et al. Clostridium difficile toxin-induced inflammation and intestinal injury are mediated by the inflammasome. Gastroenterology. (2010) 139:542-52, 552 e1-3. doi: 10.1053/j.gastro.2010.04.005

10. Liu YH, Chang YC, Chen LK, Su PA, Ko WC, Tsai YS, et al. The ATPP2X7 signaling axis is an essential sentinel for intracellular clostridium difficile pathogen-induced inflammasome activation. Front Cell Infect Microbiol. (2018) 8:84. doi: 10.3389/fcimb.2018.00084

11. Ikonen E. Roles of lipid rafts in membrane transport. Curr Opin Cell Biol. (2001) 13:470-7. doi: 10.1016/S0955-0674(00) 00238-6

12. Lafont F, Tran Van Nhieu G, Hanada K, Sansonetti P, van der Goot FG. Initial steps of Shigella infection depend on the cholesterol/sphingolipid raft-mediated CD44-IpaB interaction. EMBO J. (2002) 21:4449-57. doi: 10.1093/emboj/cdf457

13. Grassme H, Jendrossek V, Riehle A, von Kurthy G, Berger J, Schwarz H, et al. Host defense against Pseudomonas aeruginosa requires ceramide-rich membrane rafts. Nat Med. (2003) 9:322-30. doi: 10.1038/nm823

14. Lai $\mathrm{CH}$, Chang YC, Du SY, Wang HJ, Kuo CH, Fang SH, et al. Cholesterol depletion reduces Helicobacter pylori CagA translocation and CagA-induced responses in AGS cells. Infect Immun. (2008) 76:3293303. doi: 10.1128/IAI.00365-08

15. Manes S, del Real G, Martinez AC. Pathogens: raft hijackers. Nat Rev Immunol. (2003) 3:557-68. doi: 10.1038/nril129

16. Schwan C, Nolke T, Kruppke AS, Schubert DM, Lang AE, Aktories K. Cholesterol- and sphingolipid-rich microdomains are essential for microtubule-based membrane protrusions induced by Clostridium difficile transferase (CDT). J Biol Chem. (2011) 286:29356-65. doi: 10.1074/jbc.M111.261925

17. Papatheodorou P, Hornuss D, Nolke T, Hemmasi S, Castonguay J, Picchianti $\mathrm{M}$, et al. Clostridium difficile binary toxin CDT induces clustering of the lipolysis-stimulated lipoprotein receptor into lipid rafts. MBio. (2013) 4:e00244-13. doi: 10.1128/mBio.00244-13

18. Papatheodorou P, Song S, Lopez-Urena D, Witte A, Marques F, Ost GS, et al. Cytotoxicity of Clostridium difficile toxins $\mathrm{A}$ and $\mathrm{B}$ requires an active and functional SREBP-2 pathway. FASEB J. (2019) 33:488392. doi: 10.1096/fj.201801440R

19. Hung YP, Ko WC, Chou PH, Chen YH, Lin HJ, Liu YH, et al. Proton-pump inhibitor exposure aggravates clostridium difficile-associated colitis: evidence from a mouse model. J Infect Dis. (2015) 212:65463. doi: 10.1093/infdis/jiv184
20. Wright A, Wait R, Begum S, Crossett B, Nagy J, Brown K, et al. Proteomic analysis of cell surface proteins from Clostridium difficile. Proteomics. (2005) 5:2443-52. doi: 10.1002/pmic.200401179

21. Ausiello CM, Cerquetti M, Fedele G, Spensieri F, Palazzo R, Nasso M, et al. Surface layer proteins from Clostridium difficile induce inflammatory and regulatory cytokines in human monocytes and dendritic cells. Microb Infect. (2006) 8:2640-6. doi: 10.1016/j.micinf.2006.07.009

22. Schneitz C, Nuotio L, Lounatma K. Adhesion of Lactobacillus acidophilus to avian intestinal epithelial cells mediated by the crystalline bacterial cell surface layer (S-layer). J Appl Bacteriol. (1993) 74:290-4. doi: 10.1111/j.1365-2672.1993.tb03028.x

23. Grogono-Thomas R, Blaser MJ, Ahmadi M, Newell DG. Role of S-layer protein antigenic diversity in the immune responses of sheep experimentally challenged with Campylobacter fetus subsp. fetus. Infect Immun. (2003) 71:147-54. doi: 10.1128/IAI.71.1.147-154.2003

24. Merrigan MM, Venugopal A, Roxas JL, Anwar F, Mallozzi MJ, Roxas $\mathrm{BA}$, et al. Surface-layer protein A (SlpA) is a major contributor to host-cell adherence of Clostridium difficile. PLoS ONE. (2013) 8:78404. doi: 10.1371/journal.pone.0078404

25. Ryan A, Lynch M, Smith SM, Amu S, Nel HJ, McCoy CE, et al. A role for TLR4 in Clostridium difficile infection and the recognition of surface layer proteins. PLoS Pathog. (2011) 7:1002076. doi: 10.1371/journal.ppat.1002076

26. Bianco M, Fedele G, Quattrini A, Spigaglia P, Barbanti F, Mastrantonio P, et al. Immunomodulatory activities of surface-layer proteins obtained from epidemic and hypervirulent Clostridium difficile strains. J Med Microbiol. (2011) 60:1162-7. doi: 10.1099/jmm.0.029694-0

27. Alonso MA, Millan J. The role of lipid rafts in signalling and membrane trafficking in T lymphocytes. J Cell Sci. (2001) 114:3957-65.

28. Simons K, Ehehalt R. Cholesterol, lipid rafts, and disease. J Clin Invest. (2002) 110:597-603. doi: 10.1172/JCI0216390

29. Munro S. Lipid rafts: elusive or illusive? Cell. (2003) 115:37788. doi: 10.1016/S0092-8674(03)00882-1

30. Abrami L, Liu S, Cosson P, Leppla SH, van der Goot FG. Anthrax toxin triggers endocytosis of its receptor via a lipid raft-mediated clathrin-dependent process. J Cell Biol. (2003) 160:321-8. doi: 10.1083/jcb.200211018

31. Leffler DA, Lamont JT. Clostridium difficile infection. N Engl J Med. (2015) 372:1539-48. doi: 10.1056/NEJMra1403772

32. Smits WK, Lyras D, Lacy DB, Wilcox MH, Kuijper EJ. Clostridium difficile infection. Nat Rev Dis Primers. (2016) 2:16020. doi: 10.1038/nrdp.2016.20

33. Ben-Zaken O, Gingis-Velitski S, Vlodavsky I, Ilan N. Heparanase induces Akt phosphorylation via a lipid raft receptor. Biochem Biophys Res Commun. (2007) 361:829-34. doi: 10.1016/j.bbrc.2007.06.188

34. Kowalsky GB, Beam D, Oh MJ, Sachs F, Hua SZ, Levitan I. Cholesterol depletion facilitates recovery from hypotonic cell swelling in CHO cells. Cell Physiol Biochem. (2011) 28:1247-54. doi: 10.1159/000335856

35. Lai $\mathrm{CH}$, Wang HJ, Chang YC, Hsieh WC, Lin HJ, Tang $\mathrm{CH}$, et al. Helicobacter pylori CagA-mediated IL-8 induction in gastric epithelial cells is cholesterol-dependent and requires the C-terminal tyrosine phosphorylation-containing domain. FEMS Microbiol Lett. (2011) 323:155-63. doi: 10.1111/j.1574-6968.2011.02372.x

36. Heine H, Kirschning CJ, Lien E, Monks BG, Rothe M, Golenbock DT. Cutting edge: cells that carry A null allele for toll-like receptor 2 are capable of responding to endotoxin. J Immunol. (1999) 162:6971-5.

37. Xu X, Nagarajan H, Lewis NE, Pan S, Cai Z, Liu X, et al. The genomic sequence of the Chinese hamster ovary (CHO)-K1 cell line. Nat Biotechnol. (2011) 29:735-41. doi: 10.1038/nbt.1932

38. Predrag S, Branislava K, Miodrag S, Biljana MS, Suzana T, Natasa MT, et al. Clinical importance and representation of toxigenic and non-toxigenic Clostridium difficile cultivated from stool samples of hospitalized patients. Braz J Microbiol. (2012) 43:215-23. doi: 10.1590/S1517-838220120001 00023

39. Wang CY, Liu PY, Liao JK. Pleiotropic effects of statin therapy: molecular mechanisms and clinical results. Trends Mol Med. (2008) 14:37-44. doi: 10.1016/j.molmed.2007.11.004

40. McGuire T, Dobesh P, Klepser D, Rupp M, Olsen K. Clinically important interaction between statin drugs and Clostridium difficile toxin? Med Hypotheses. (2009) 73:1045-7. doi: 10.1016/j.mehy.2009.06.058 
41. Motzkus-Feagans CA, Pakyz A, Polk R, Gambassi G, Lapane KL. Statin use and the risk of Clostridium difficile in academic medical centres. Gut. (2012) 61:1538-42. doi: 10.1136/gutjnl-2011-301378

Conflict of Interest: The authors declare that the research was conducted in the absence of any commercial or financial relationships that could be construed as a potential conflict of interest.
Copyright (c) 2020 Chen, Huang, Chen, Wu, Hsu, Tsai, Ko and Tsai. This is an open-access article distributed under the terms of the Creative Commons Attribution License (CC BY). The use, distribution or reproduction in other forums is permitted, provided the original author(s) and the copyright owner $(s)$ are credited and that the original publication in this journal is cited, in accordance with accepted academic practice. No use, distribution or reproduction is permitted which does not comply with these terms. 